\title{
The "Guidewire-Coil"-Technique to prevent retrograde stone migration of ureteric calculi during intracorporeal lithothripsy
}

\author{
Nici Markus Dreger ${ }^{1 *}$, Friedrich Carl von Rundstedt ${ }^{2,3}$, Stephan Roth ${ }^{1}$, Alexander Sascha Brandt ${ }^{1}$ \\ and Stephan Degener ${ }^{1}$
}

\begin{abstract}
Background: Stone retropulsion represents a challenge for intracorporeal lithotripsy of ureteral calculi. The consequences are an increased duration and cost of surgery as well as decreased stone-free rates. The use of additional tools to prevent proximal stone migration entails further costs and risks for ureteral injuries. We present the simple technique of using a coil of the routinely used guidewire to prevent stone retropulsion.

Methods: We retrospectively evaluated all patients with mid-to-proximal ureteral stones in 2014, which were treated by ureteroscopic lithotripsy (Ho: YAG and/or pneumatic lithotripsy). The preoperative stone burden was routinely assessed using low dose CT scan (if available) and/or intravenous pyelogram.

Results: The study population consisted of 55 patients with 61 mid-to-proximal calculi. Twentyseven patients underwent semirigid ureterorenoscopy using the "Guidewire-Coil-Technique", the second group $(n=28)$ served as control group using the guidewire as usual. There has been a statistically significant reduction of accidental stone retropulsion $(2 / 27$ vs. $8 / 28, p<0.05)$ as well as a decreased use of auxiliary procedures $(p<0.05)$ compared to the control group. No difference was observed in operative time. One ureteral injury in the control group required a prolonged ureteral stenting.

Conclusion: The "Guidewire-Coil-Technique" is a simple and safe procedure that may help to prevent proximal calculus migration and therefore may increase stone-free rates without causing additional costs.
\end{abstract}

Keywords: Stone migration, Stone retropulsion, Intracorporeal lithotripsy, Ureterorenoscopy, Ureteric calculi

\section{Background}

During the past two decades, there have been many improvements regarding the endoscopic treatment of urolithiasis. Ureterorenoscopy (URS) with and without lithotripsy is a standard method to treat ureteral calculi depending on different factors including location, stone size, individual patient factors as well as equipping $[1,2]$. A particular challenge limiting the success of ureteroscopic lithotripsy is stone retropulsion due to insertion of the ureteroscope, pressure by the irrigation fluid and/or the lithotripsy itself [2]. Stone migration occurs in

\footnotetext{
* Correspondence: nici-markus.dreger@helios-kliniken.de

${ }^{1}$ Department of Urology, Helios Medical Center Wuppertal, Helios University Hospital Wuppertal, University of Witten/Herdecke, Heusnerstraße 40, Wuppertal 42283, Germany

Full list of author information is available at the end of the article
}

$28-60 \%$ of proximal calculi [3-6]. Hereby an increase in operative time, a decrease in stone-free rates and the need for further auxiliary procedures (i.e. shockwave lithotripsy (SWL), flexible ureterorenoscopy (fURS)) with affiliated morbidities and health-care costs have been reported $[2,7,8]$. Novel stone retrieval devices have been introduced to address the problem of accidental stone migration: Stone baskets $[9,10]$, suction devices [11], balloon catheters [12,13] guidewire [14-16] and gelbased devices $[17,18]$ significantly reduced the incidence of stone retropulsion. On the contrary, these devices are associated with additional costs and some of them with a higher risk for ureteral injuries [2].

Because of this predicament, we assessed a new technique only using the usually recommended guidewire to 
prevent proximal stone migration. We here describe our experience and the efficacy of this method.

\section{Methods}

From January 2014 to December 2014, 55 patients with upper ureteral calculi $(n=61)$ were treated in our institution by primary intracorporeal lithotripsy according to the current guidelines [19]. Preoperative stone location and size were confirmed by abdomen and pelvis computed tomography (CT) scan or in rare cases by intravenous pyelography (IVP), if CT scan was not available. All patients underwent semirigid ureterorenoscopy and intracorporeal lithotripsy has been performed using holmium-YAG laser (Ho:YAG) and/or pneumatic lithotriptor. The "Guidewire-Coil-Technique" in this study was performed by a single faculty urologist (S.R.) with more than 2000 ureterorenoscopies. IRB approval was obtained (no. 43/2016, Witten/Herdecke University).

All 55 patients were analyzed retrospectively: Of these patients 27 were treated using the "Guidewire-CoilTechnique" and 28 patients served as control group using the guidewire in regular fashion. Plain film radiographs of the kidneys, ureters, and bladder (KUB) and sonography were obtained to verify stone-free rate and migration rate.

Patients were stratified by the kind of use of the guidewire. The primary endpoint was the stone-free rate. The incidence of stone retropulsion, need for further auxiliary procedures, operative time and complication rate were defined as secondary endpoints. Statistical assessment was performed using Fisher's exact test for categorical variables and Mann-Whitney $U$ test for continuous variables respectively. $P$ values $<0.05$ were considered significant. Statistical analysis was performed using SPSS $21^{\circ}$ for $\mathrm{Mac}^{\circ}$ (SPSS Inc., Chicago, IL, USA).

\section{The "Guidewire-Coil-Technique"}

In all patients a hydrophilic guidewire with nitinol core and angled tip (outer diameter $0.89 \mathrm{~mm}(0.035$ "), length $150 \mathrm{~cm}$, flexible length $30 \mathrm{~mm}$ ) was used. In our case series, we used a $9.8 \mathrm{~F}$ ( $8 \mathrm{~F}$ tip, $9.8 \mathrm{~F}$ base) semirigid ureteroscope (Karl Storz, Germany) with a $5 \mathrm{~F}$ working channel. After careful retrograde pyelography (RPG, Figs. 1a-b, 2a-b), the guidewire is advanced beyond the stone. After reaching the renal pelvis, the angled tip was placed in the upper calix and then pushed until a loop of the guidewire was achieved. The loop in the upper calix facilitates a direct turn back into the ureter (and prevents a coiling in renal pelvis without turn back in the ureter). By rotating the guidewire manually or with a Halstead clamp (can be helpful with clammy gloves), the angled tip can be used to navigate the guidewire in the desired direction. Additionally, we don't recommend a guidewire with a straight distal curve because it's stiffness makes a precise loop in the upper calix much more difficult. The reverted guidewire was placed consecutively directly proximal to the stone (Fig. 1c). At this position, the reverted guidewire acts as a counterfort, which will help to prevent retrograde stone migration during intracorporeal lithotripsy (Figs. 2c and 3).

\section{Results}

The two groups were comparable with regard to gender, age, size or location (Table 1). Upward stone or fragment retropulsion to the kidney occurred in two patients $(7.4 \%)$ in the treatment and eight patients $(28.6 \%)$ in the control group, a statistically significant difference $(p<0.05$, Table 2$)$. In the treatment group a guidewire coiling could be achieved in every patient after 1-8 attempts (median 3 attempts). There was no relevant difference concerning the mean operative

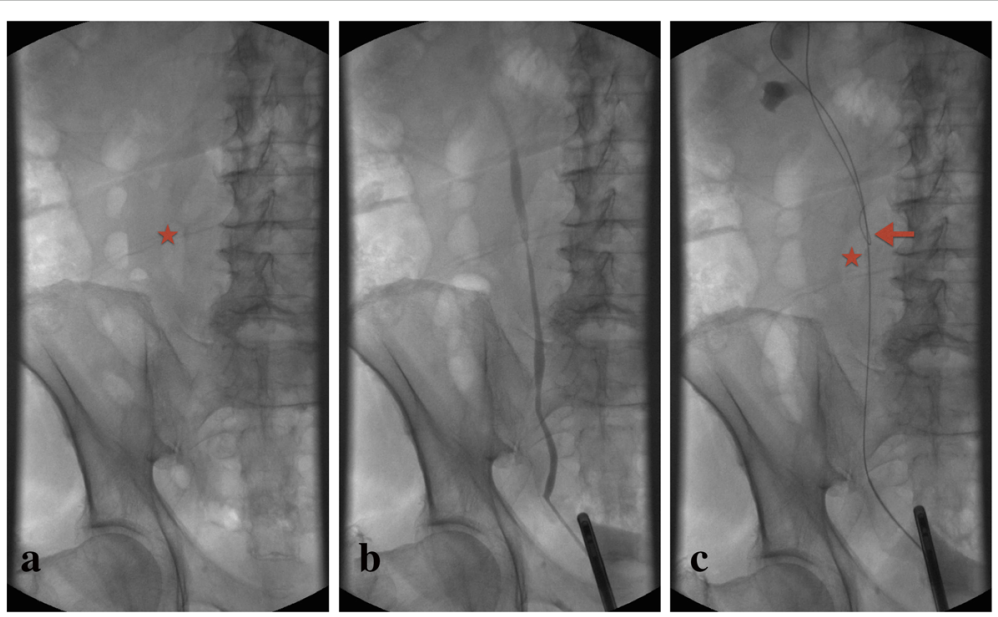

Fig. 1 Step-by-step description of the "Guidewire-Coil-Technique" based on the example of a mid ureteric stone. a: Plain x-ray; b: Retrograde pyelography; c: Correctly placed coil of the guidewire. Asterisk = Ureteral calculus, arrow= Reverted guidewire acting as a counterfort 


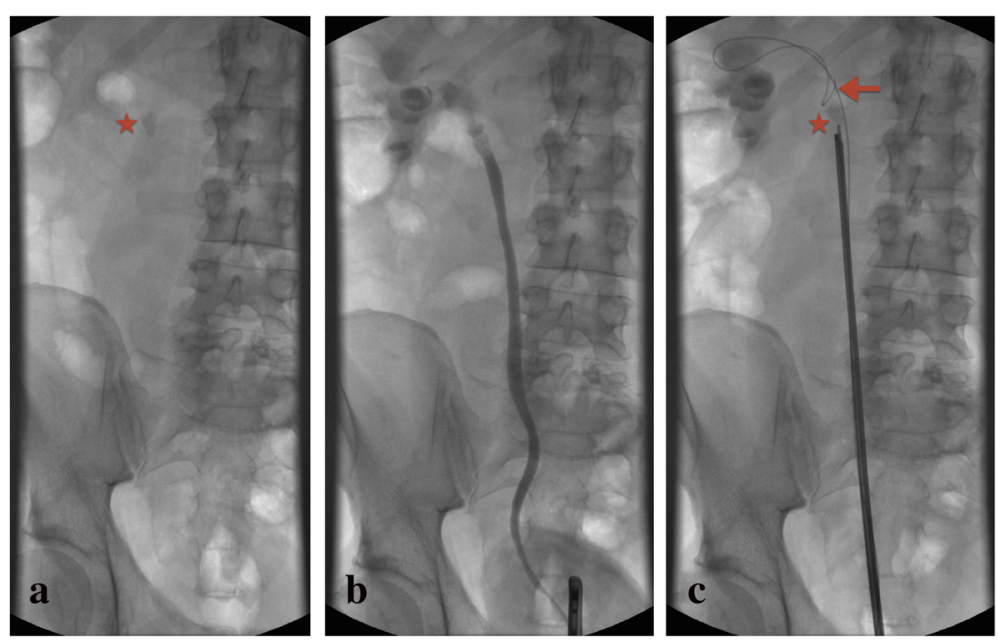

Fig. 2 Step-by-step description of the "Guidewire-Coil-Technique" based on the example of a proximal stone. a: Plain x-ray; b: Retrograde pyelography; c: Correctly placed coil of the guidewire. Asterisk =Ureteral calculus, arrow = Reverted guidewire acting as a counterfort

time (67.6 versus 70.3 minutes, $p=0.901)$ and the type of lithotripsy used for fragmentation of the stones (Ho:YAG versus pneumatic lithotripsy, $p=$ 0.500). Auxiliary procedures such as flexible ureterorenoscopy were necessary in three patients $(11 \%)$ in the treatment group compared to ten patients $(35.7 \%)$ in the control group $(p<0.05)$. Postoperatively, patients were followed up with KUB and sonography as described before. The stone-free rates were $92.6 \%$ in the treatment and $75 \%$ in the control group, respectively. The difference between the two groups was statistically borderline significant $(p=0.079)$. Only one notable ( $\geq$ III, classified according to the Clavien system) complication was observed: one patient (3.6\%) in the control group had a ureteral wall injury, which resulted in a prolonged ureteral stenting.

\section{Discussion}

Stones larger than $5 \mathrm{~mm}$ in diameter require intracorporeal fragmentation before extraction through the ureteroscope [20]. A wide variety of endoscopic lithotriptors have become available for stone fragmentation including laser, electrohydraulic and the pneumatic lithotriptor. The ballistic nature of the energy occasionally displaces calculi towards the kidney. Stone migration into the collecting system makes stone retrieval substantially more challenging especially into a lower pole or anterior calyx, which necessitates additional procedures such as adjuvant extracorporeal SWL $[8,21]$.

Novel stone retrieval devices have been recommended for the prevention of retrograde stone displacement including ureteral stone baskets, balloon catheters, stone cone, etc. (Table 3). However, all of these add to the costs and some increase the risk for ureteral injuries [2].

The stone-free rate in the current work was different between the 2 groups $(92.6 \%$ for the treatment group and $75 \%$ for the control group). The control group consequently had a higher rate of ancillary procedures as reflected by the significantly different efficiency quotient. This was partly due to stone retropulsion requiring an auxiliary procedure. In comparison to the before mentioned (expensive) stone retrieval devices and their associated stone-free rates (Table 3), our technique was not inferior.
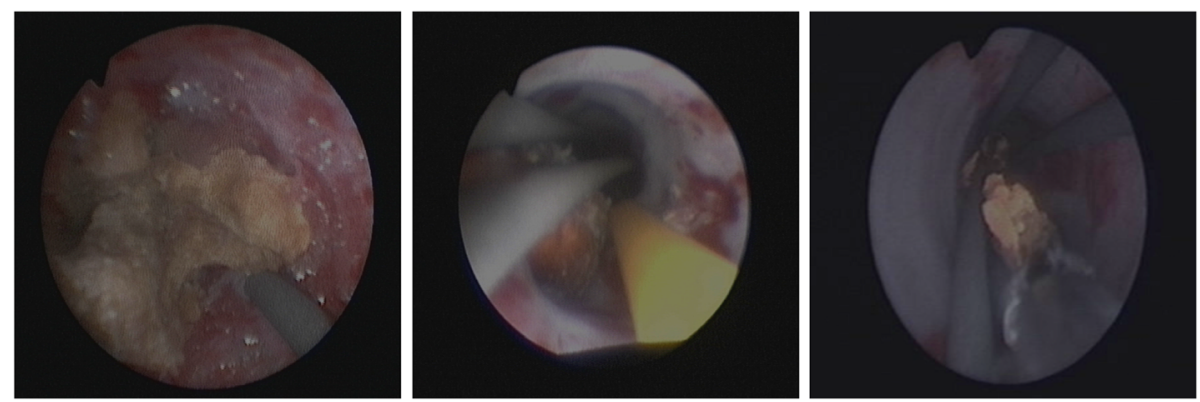

Fig. 3 Examples of the endoscopic point of view while using the "Guidewire-Coil-Technique" 
Table 1 Preoperative characteristics of both groups

\begin{tabular}{|c|c|c|c|c|c|}
\hline & $\begin{array}{l}\text { Guidewire-Coil } \\
n=27\end{array}$ & & $\begin{array}{l}\text { Control } \\
n=28\end{array}$ & & $P$ value \\
\hline & & $\pm S D$ & & $\pm \mathrm{SD}$ & \\
\hline Gender & & & & & $0.527^{\dagger}$ \\
\hline Male & 22 & & 22 & & \\
\hline Female & 5 & & 6 & & \\
\hline \multicolumn{6}{|l|}{ Age [a] } \\
\hline Mean & 58.0 & 16.0 & 55.0 & 15.5 & $0.622^{*}$ \\
\hline Median & 54.0 & & 56.5 & & \\
\hline Number of stones & 28 & & 33 & & \\
\hline \multicolumn{6}{|l|}{ Size $[\mathrm{mm}]$} \\
\hline Mean & 9.8 & 3.4 & 10.0 & 3.5 & $0.953^{*}$ \\
\hline Median & 8.6 & & 9.2 & & \\
\hline \multicolumn{6}{|l|}{ Calculus location } \\
\hline Proximal ureter & 13 & & 15 & & $0.571^{\dagger}$ \\
\hline Mid ureter & 15 & & 18 & & \\
\hline
\end{tabular}

$S D=$ standard deviation

*Significant at $p$ value $<0.05$ by Mann-Whitney test

${ }^{+}$Significant at $p$ value $<0.05$ by Fisher's-exact test

Table 2 Postoperative comparison of both groups

\begin{tabular}{|c|c|c|c|c|c|}
\hline & $\begin{array}{l}\text { Guidewire-Coil } \\
n=27\end{array}$ & & $\begin{array}{l}\text { Control } \\
n=28\end{array}$ & & $P$ value \\
\hline & & $\pm \mathrm{SD}$ & & $\pm \mathrm{SD}$ & \\
\hline \multicolumn{6}{|l|}{ Operative time [min] } \\
\hline Mean & 67.6 & 29.8 & 70.3 & 34.0 & $0.901^{*}$ \\
\hline Median & 61.0 & & 58.5 & & \\
\hline Stone migration & & & & & $0.044^{\dagger}$ \\
\hline Yes & $2[7.4 \%]$ & & 8 [28.6\%] & & \\
\hline No & 25 & & 20 & & \\
\hline Auxiliary procedures & & & & & $0.032^{\dagger}$ \\
\hline Yes & 3 [11\%] & & 10 [35.7\%] & & \\
\hline Flexible URS & 2 & & 5 & & \\
\hline SWL & 0 & & 4 & & \\
\hline Secondary URS & 0 & & 1 & & \\
\hline No & 24 & & 18 & & \\
\hline Stone-free rate & & & & & $0.079^{\dagger}$ \\
\hline Yes & 25 [92.6\%] & & 21 [75\%] & & \\
\hline No & 2 & & 7 & & \\
\hline Lithotripsy & & & & & $0.500^{\dagger}$ \\
\hline Ho:YAG & 20 & & 19 & & \\
\hline Pneumatic & 8 & & 9 & & \\
\hline
\end{tabular}

Operative time was determined using the anesthesia protocols $S D=$ standard deviation; URS = ureterorenoscopy; $\mathrm{Ho}: \mathrm{YAG}=$ Holmium-YAG laser lithotripter

*Significant at $p$ value $<0.05$ by Mann-Whitney test

${ }^{+}$Significant at $p$ value $<0.05$ by Fisher's-exact test
Table 3 Overview of different devices and techniques to prevent accidental stone migration

\begin{tabular}{|c|c|c|c|c|c|}
\hline Author & Year & Device/Technique & $n$ & $\begin{array}{l}\text { Stone } \\
\text { migration [\%] }\end{array}$ & SFR [\%] \\
\hline $\begin{array}{l}\text { Kesler } \\
\text { et al. [10] }\end{array}$ & 2008 & $\begin{array}{l}\text { Stone basket } \\
\left.\text { (Escape }^{\oplus}\right)\end{array}$ & 23 & n.a. & 87 \\
\hline $\begin{array}{l}\text { Eisner } \\
\text { et al. [22] }\end{array}$ & 2009 & $\begin{array}{l}\text { Guidewire } \\
\left.\text { (Stone Cone }^{\oplus}\right)\end{array}$ & 133 & 1.5 & 98.5 \\
\hline $\begin{array}{l}\text { Sen } \\
\text { et al. [23] }\end{array}$ & 2014 & $\begin{array}{l}\text { Guidewire } \\
\text { (Stone Cone }^{\oplus} \text { ) }\end{array}$ & 25 & 4.5 & 95.5 \\
\hline $\begin{array}{l}\text { Sen } \\
\text { et al. [23] }\end{array}$ & 2014 & $\begin{array}{l}\text { Guidewire } \\
\left.\text { (PercSys }^{\oplus}\right)\end{array}$ & 25 & 8.7 & 91.3 \\
\hline $\begin{array}{l}\text { Wang } \\
\text { et al. [24] }\end{array}$ & 2011 & $\begin{array}{l}\text { Guidewire } \\
\left.(\text { NTrap })^{\oplus}\right)\end{array}$ & 56 & 0.0 & 100 \\
\hline $\begin{array}{l}\text { Sen } \\
\text { et al. [23] }\end{array}$ & 2014 & $\begin{array}{l}\text { Gel-based } \\
\text { (Lidocaine jelly) }\end{array}$ & 25 & 21.7 & 82.6 \\
\hline $\begin{array}{l}\text { Mohseni } \\
\text { et al. [18] }\end{array}$ & 2006 & $\begin{array}{l}\text { Gel-based } \\
\text { (Lidocaine jelly) }\end{array}$ & 16 & 12.4 & 93.7 \\
\hline $\begin{array}{l}\text { Rane } \\
\text { et al. [25] }\end{array}$ & 2010 & $\begin{array}{l}\text { Thermosensitive } \\
\left.\text { polymer (BackStop }{ }^{\oplus}\right)\end{array}$ & 34 & 8.8 & 87.8 \\
\hline $\begin{array}{l}\text { Dretler } \\
\text { et al. [13] }\end{array}$ & 2000 & $\begin{array}{l}\text { Balloon catheter } \\
\left.\text { (Passport }{ }^{\oplus}\right)\end{array}$ & 29 & 10.3 & 89.7 \\
\hline
\end{tabular}

In two patients in the group managed with the guidewire-coil-technique we were not able to prevent stone migration towards the kidney. While we did not observe any proximal stone migration during the placement of the wire there may be an association with the diameter of the dilated ureter (similar to balloon catheters) $[2,13]$. Although possible in every patient in the treatment group, it took 1-8 (median 3 ) attempts to coil the guidewire in the renal pelvis and get a loop back into the ureter. To our experience the most important step is a direct loop in the upper calix to achieve a quick and direct turn back into the ureter. We do acknowledge that there there is a learning curve to the procedure but the steps are easily learned by the residents in our programme. Furthermore there might be anatomical conditions that make this step of the procedure challenging (e.g. a duplex collecting system).

Contrary to our expectations, we did not observe significant differences in operative time between the two groups (67.6 versus $70.3 \mathrm{~min}, P=0.901$ ). While multiple attempts of directing the guidewire back in the ureter can be time consuming it has been our experience that the actual procedure can be performed more efficiently and possibly faster because of a higher flow of irrigation fluid. This can result in improved vision without an increased risk of stone retropulsation.

This was not a prospective study. Patients were not randomized. By that, the retrospective character and the small number of patients are limitations of this study. Nevertheless, we were able to show the feasibility of this technique and its potential utility in the prevention of stone migration during ureteroscopy and lithotripsy. 


\section{Conclusion}

Coiling the routinely used guidewire just proximal to the stone in the ureter prior to lithotripsy during ureteroscopy may be a simple and inexpensive option to significantly reduce inadvertent stone migration and achieve higher stone-free rates.

\section{Abbreviations}

CT: Computerized tomography; fURS: Flexible ureterorenoscopy; Ho:YAG: Holmium:YAG laser; IRB: Institutional review board; IVP: Intravenous pyelography; KUB: Plain film radiographs of the kidneys, ureters, and bladder; SWL: Shock wave lithotripsy; URS: Ureterorenoscopy

\section{Acknowledgements}

None.

\section{Availability of data and materials}

The datasets used and/or analysed during the current study available from the corresponding author on reasonable request.

\section{Authors' contribution}

NMD and SD have made substantial contributions to conception and design acquisition of data as well as analysis and interpretation of data; have been involved in drafting the manuscript and have given final approval of the version to be published. FCvonR, SR and ASB made substantial contributions to conception and design as well as interpretation of data; have been involved in revising the manuscript critically for important intellectual content; have given final approval of the version to be published. Each author has participated sufficiently in the work to take public responsibility for appropriate portions of the content and agreed to be accountable for all aspects of the work in ensuring that questions related to the accuracy or integrity of any part of the work are appropriately investigated and resolved.

\section{Competing interests}

The authors declare that they have no competing interests.

\section{Consent for publication}

Not applicable.

\section{Ethics approval and consent to participate}

Each patient gave informed consent and the study was approved by the institutional review committee of Witten/Herdecke University (no. 43/2016).

\section{Author details}

'Department of Urology, Helios Medical Center Wuppertal, Helios University Hospital Wuppertal, University of Witten/Herdecke, Heusnerstraße 40, Wuppertal 42283, Germany. ${ }^{2}$ Scott Department of Urology, Baylor College of Medicine Medical Center, 7200 Cambridge, Houston, TX, USA. ${ }^{3}$ Department of Urology, Jena Medical Center, Friedrich-Schiller University, Bachstraße 18, Jena 07743, Germany.

Received: 23 October 2016 Accepted: 26 December 2016

Published online: 05 January 2017

\section{References}

1. Ahmed M, Pedro RN, Kieley S, Akornor JW, Durfee WK, Monga M. Systematic evaluation of ureteral occlusion devices: insertion, deployment, stone migration, and extraction. Urology. 2009;73(5):976-80.

2. Elashry OM, Tawfik AM. Preventing stone retropulsion during intracorporeal lithotripsy. Nat Rev Urol. 2012;9(12):691-8.

3. Chow GK, Patterson DE, Blute ML, Segura JW. Ureteroscopy: effect of technology and technique on clinical practice. J Urol. 2003;170(1):99-102.

4. Knispel HH, Klan R, Heicappell R, Miller K. Pneumatic lithotripsy applied through deflected working channel of miniureteroscope: results in 143 patients. J endourol Soc. 1998;12(6):513-5.

5. Osorio L, Lima E, Soares J, Autorino R, Versos R, Lhamas A, Marcelo F. Emergency ureteroscopic management of ureteral stones: why not? Urology. 2007;69(1):27-31. discussion 31-23.
6. Tunc L, Kupeli B, Senocak C, Alkibay T, Sozen S, Karaoglan U, Bozkirli I. Pneumatic lithotripsy for large ureteral stones: is it the first line treatment? Int Urol Nephrol. 2007;39(3):759-64.

7. Dretler SP. The stone cone: a new generation of basketry. J Urol. 2001; 165(5):1593-6.

8. Lee H, Ryan RT, Teichman JM, Kim J, Choi B, Arakeri NV, Welch AJ. Stone retropulsion during holmium:YAG lithotripsy. J Urol. 2003;169(3):881-5.

9. El-Gabry EA, Bagley DH. Retrieval capabilities of different stone basket designs in vitro. J Endourol Soc. 1999;13(4):305-7.

10. Kesler SS, Pierre SA, Brison DI, Preminger GM, Munver R. Use of the Escape nitinol stone retrieval basket facilitates fragmentation and extraction of ureteral and renal calculi: a pilot study. J Endourol Soc. 2008;22(6):1213-7.

11. Delvecchio FC, Kuo RL, Preminger GM. Clinical efficacy of combined lithoclast and lithovac stone removal during ureteroscopy. J Urol. 2000; 164(1):40-2.

12. Dellabella M, Milanese G, d'Anzeo G, Muzzonigro G. Rapid, economical treatment of large impacted calculi in the proximal ureter with ballistic ureteral lithotripsy and occlusive, percutaneous balloon catheter: the high pressure irrigation technique. J Urol. 2007;178(3 Pt 1):929-33. discussion 933-924.

13. Dretler SP. Ureteroscopy for proximal ureteral calculi: prevention of stone migration. J Endourol Soc. 2000;14(7):565-7.

14. Ding $H$, Wang Z, Du W, Zhang H. NTrap in prevention of stone migration during ureteroscopic lithotripsy for proximal ureteral stones: a meta-analysis. J Endourol Soc. 2012;26(2):130-4

15. Maislos SD, Volpe M, Albert PS, Raboy A. Efficacy of the Stone Cone for treatment of proximal ureteral stones. J Endourol Soc. 2004;18(9):862-4.

16. Pagnani CJ, El Akkad M, Bagley DH. Prevention of stone migration with the accordion during endoscopic ureteral lithotripsy. J Endourol Soc. 2012;26(5):484-8

17. Ali AA, Ali ZA, Halstead JC, Yousaf MW, Ewah P. A novel method to prevent retrograde displacement of ureteric calculi during intracorporeal lithotripsy. BJU Int. 2004:94(3):441-2.

18. Mohseni MG, Arasteh S, Alizadeh F. Preventing retrograde stone displacement during pneumatic lithotripsy for ureteral calculi using lidocaine jelly. Urology. 2006;68(3):505-7.

19. Preminger GM, Tiselius HG, Assimos DG, Alken P, Buck C, Gallucci M, Knoll T, Lingeman JE, Nakada SY, Pearle MS, et al. 2007 guideline for the management of ureteral calculi. J Urol. 2007:178(6):2418-34

20. Leveillee RJ, Lobik L. Intracorporeal lithotripsy: which modality is best? Curr Opin Urol. 2003;13(3):249-53.

21. Aghamir SK, Mohseni MG, Ardestani A. Treatment of ureteral calculi with ballistic lithotripsy. J Endourol Soc. 2003;17(10):887-90.

22. Eisner BH, Dretler SP. Use of the stone cone for prevention of calculus retropulsion during holmium:YAG laser lithotripsy: case series and review of the literature. Urol Int. 2009:82(3):356-60.

23. Sen H, Bayrak O, Erturhan S, Urgun G, Kul S, Erbagci A, Seckiner I. Comparing of different methods for prevention stone migration during ureteroscopic lithotripsy. Urol Int. 2014;92(3):334-8.

24. Wang CJ, Huang SW, Chang CH. Randomized trial of NTrap for proximal ureteral stones. Urology. 2011;77(3):553-7.

25. Rane A, Bradoo A, Rao P, Shivde S, Elhilali M, Anidjar M, Pace K, JR DAH. The use of a novel reverse thermosensitive polymer to prevent ureteral stone retropulsion during intracorporeal lithotripsy: a randomized, controlled trial. J Urol. 2010:183(4):1417-21. 